\title{
Power Spectral Analysis of Heart Rate Variability in Female Rheumatoid Arthritis Patients
}

\author{
Kawser Jahan ${ }^{1}$, Noorzahan Begum ${ }^{2}$, Sultana Ferdousi ${ }^{3}$
}

\begin{abstract}
Background: Association of increased cardiovascular morbidity and higher sympathetic activity in patients with Rheumatoid arthritis (RA) has been recognized. Heart rate variability (HRV) is a useful measure to assess sympatho-vagal balance. Objective: To assess autonomic nerve function status in patients with Rheumatoid Arthritis (RA) by HRV analysis. Methods: This cross sectional study was conducted in the Department of Physiology, Bangabandhu Sheikh Mujib Medical University (BSMMU), Shahbag, Dhaka from January to December 2010. Sixty female RA patients aged 18-50 years were included in the study group. They were enrolled from the Out Patient Department of Rheumatology Wing of the Department of Medicine, BSMMU, Dhaka. For comparison age matched thirty apparently healthy females were also studied as control. The HRV parameters were recorded by a Polyrite machine. For statistical analysis independent sample t test was used. Results: Mean resting pulse rate, diastolic blood pressure and mean systolic blood pressure were higher in rheumatoid arthritis patients in comparison to those of healthy control. Mean values of LF power, LF norm and LF/ HF were significantly higher $(p<0.001) \&$ TP and HF power, HF norm were significantly lower $(p<0.001)$ in RA patients in comparison to those of healthy control. Conclusion: This study may conclude that sympathetic activity was higher with lower parasympathetic activity along with shifting of sympathovagal balance towards sympathetic predominance in patients with rheumatoid arthritis.
\end{abstract}

Key words: LF, HF, LF norm, HF norm, LF/HF, Rheumatoid Arthritis

J Bangladesh Soc Physiol. 2012 June; 7(1): 8-12 For Authors Affiliation, see end of text.

http://www.banglajol.info/index.php/JBSP

\section{Introduction}

$\mathbf{R}$ heumatoid arthritis is a chronic inflammatory disease of the joints in which pain, swelling and limited mobility of the joints are the most prominent features. ${ }^{1}$ It is a common inflammatory connective tissue and it's prevalence rate varies among different groups of population. Worldwide prevalence of RA is $1 \%$ and in Bangladesh it is also almost same. ${ }^{2}$ Women are affected 2 to 3 times more than men. Onset may be at any age

Received February 2012; $\quad$ Accepted May 2012 but most commonly occur between $3^{\text {rd }}$ to $5^{\text {th }}$ decades of life. ${ }^{3-5}$ It has been known that Rheumatoid Arthritis is associated with increased mortality. ${ }^{6}$

Most recently, Johns Hopkins specialists reported link between rheumatoid arthritis and heart health. ${ }^{7}$ Though cardiac involvement is silent, but cardiovascular mortality is also higher in RA patients. ${ }^{1,8,9}$

Rheumatoid arthritis may alter autonomic nerve function and may produce sympathovagal

J Bangladesh Soc Physiol. 2012, June; 7(1): 8-12 
imbalance. ${ }^{10-12}$ Though both peripheral and central nervous system involvement has been well recognized but information on involvement of autonomic nervous system is scarcely available. $^{10}$

Heart rate variability (HRV) reflects autonomic nervous control. Normally HR variation is related to the balance between sympathetic \& parasympathetic nervous system which provides early better quantitative and qualitative interpretation of sympathovagal modulation and can detect autonomic impairment. ${ }^{11}$

High HRV reflects good adaptability and well functioning autonomic nervous control. On the other hand, reduced heart rate variability acts as a strong predictor of risk for adverse events in patients with wide range of diseases including RA. ${ }^{11}$

Power spectral analysis of HRV can demonstrate definite impairment in cardiac autonomic control. ${ }^{13}$

Lower values of LF, HF, HF norm and LF norm were reported by various investigators of different countries in patients with rheumatoid arthritis in comparison with those of healthy control. $11,12,14,15$

On the contrary, higher LF, LF/HF were observed by some investigators in patients with RA when compared with those of healthy control. ${ }^{11,15}$

RA is one of the common systemic diseases in our country and is an important cause of disability, morbidity and mortality in the affected people. Nearly half of the deaths occur in RA due to cardiovascular disease (CVD). ${ }^{16}$ Autonomic dysfunction has also been detected in RA patients. ${ }^{17}$ Though most of the cardiovascular disorders remain unnoticed, it is possible to prevent the development of various cardiac complications.

Therefore, this study was carried out to assess cardiac autonomic nerve function status in RA patients by HRV spectral parameters. This study

J Bangladesh Soc Physiol. 2012, June; 7(1): 8-12 may signify the importance of screening of autonomic nerve function status in RA patients in order to minimize the risk of cardiac autonomic impairment related complications. This may also be helpful for appraisal of clinicians about the silent existence of autonomic nerve dysfunction and cardiovascular disorders while treating the RA patient.

\section{Methods}

This cross sectional study was carried out to observe the autonomic nerve function by power spectral analysis of HRV in 60 female patients with Rheumatoid arthritis aged from 18 to 50 years. They were diagnosed according to American College of Rheumatology (ACR) classification $^{4,18}$. Female RA patients were selected as case as they were more affected than male. For comparison, 30 age and BMI matched apparently healthy females were also studied. This study was conducted in the Department of Physiology, Bangabandhu Sheikh Mujib Medical University (BSMMU), Dhaka from January 2010 to December 2010. Rheumatoid Arthritis patients were selected from the Out Patient Department of Rheumatology Wing of the Department of Medicine, BSMMU, Dhaka and control group was selected from the employee of BSMMU. The study protocol was approved by Ethical Review Committee of BSMMU. RA patients with history of hypertension, heart disease, diabetes mellitus, renal diseases and psychic disorders were excluded from the study.

After selection, the subject was thoroughly informed about the aim, objectives and procedure of the study and was encouraged for voluntary participation. An informed written consent was taken from each subject. The subjects were advised to have their meal by 9:00 pm on the previous night, not to take sedatives or any drugs affecting central nervous system, to have sound sleep at night before the test and also advised to remain free from any physical or mental stress. They were also requested to have light breakfast without tea or coffee and then to attend the Autonomic 
Nerve Function Laboratory in the Department of Physiology of Bangabandhu Sheikh Mujib Medical University between 9:00 to 11:00 a.m. on the day of test. Whenever she appeared in the department, detail history regarding personal history, drug history, and medical history were taken. Then thorough Physical examinations and anthropometric measurement including height, weight and BMI were measured. All information were recorded in a pre-fixed questionnaire. Then she was asked to lie on a bed in supine position and was allowed to take rest for 15 minutes in a cool and calm environment at Autonomic Nerve Function Test Laboratory. During the test period she was restricted to talk, eat, drink, any physical or mental activity and even sleep. Then standard lead II of the ECG channel of a digital Polyrite machine was connected and a 5 minutes recording was taken in resting supine position. Power spectral parameters of Heart Rate Variability like Total power (TP), LF norm, HF norm, LF/HF were measured by a polygraph (RMS Polyrite $\mathrm{D}$, version 2.2). For statistical analysis Independent sample t-test was performed.

\section{Results}

Baseline data are shown in table I. All the groups are matched for age and BMI.

The mean resting pulse rate $(\mathrm{p}<0.05)$ and DBP $(\mathrm{p}<0.001)$ were significantly higher and mean SBP was higher but statistically non significant $(p<0.05)$ in RA patients than those of control. The mean total power, HF power and HF norm $(p<0.001)$ were significantly lower and LF power, LF norm and LF/HF $(p<0.001)$ were significantly higher in RA patients. (Table II)

Table I: Baseline characteristics in different groups $(n=90)$

\begin{tabular}{lccc}
\hline Variables & Group $\mathrm{A}(\mathrm{n}=30)$ & Group B $(\mathrm{n}=60)$ & $\mathrm{p}$ value \\
\hline Age $($ years $)$ & $36.50 \pm 11.50$ & $37.09 \pm 11.10$ & $0.803^{\mathrm{ns}}$ \\
BMI $\left(\mathrm{Kg} / \mathrm{m}^{2}\right)$ & $23.88 \pm 2.27$ & $23.94 \pm 1.68$ & $0.876^{\mathrm{ns}}$ \\
Pulse (beat $/ \mathrm{min})$ & $80.29 \pm 10.62$ & $85.34 \pm 11.22$ & $0.03^{*}$ \\
SBP(mm of $\mathrm{Hg})$ & $114.37 \pm 11.79$ & $116.19 \pm 11.30$ & $0.451^{\mathrm{ns}}$ \\
DBP(mm of $\mathrm{Hg})$ & $68.70 \pm 7.59$ & $73.77 \pm 7.01$ & $0.001^{* *}$ \\
\hline
\end{tabular}

Data were expressed as mean \pm SD. Statistical analysis was done by Independent sample t-test. Group A: Apparently healthy people. Group B: Patients with Rheumatoid arthritis

$\mathrm{BMI}=$ Body Mass index, $\mathrm{SBP}=$ Systolic blood pressure, $\mathrm{DBP}=$ Diastolic blood pressure. ${ }^{* *}=\mathrm{p}<0.01,{ }^{*}=\mathrm{p}<0.05$, $n s=p>0.05, n=$ number of subjects. $n s=$ nonsignificant

Table II: Power spectral measures of HRV in different groups $(\mathrm{n}=90)$

\begin{tabular}{lccc}
\hline Variables & Group $\mathrm{A}(\mathrm{n}=30)$ & Group B(n=60) & $\mathrm{p}$ value \\
\hline Total power( $\left(\mathrm{ms}^{2}\right)$ & $2677.7 \pm 206.26$ & $1427.41 \pm 224.24$ & $0.000^{* * *}$ \\
LF $\left(\mathrm{ms}^{2}\right)$ & $846.25 \pm 83.80$ & $914.11 \pm 185.74$ & $0.05^{*}$ \\
HF $\left(\mathrm{ms}^{2}\right)$ & $514.86 \pm 129.42$ & $232.84 \pm 67.59$ & $0.000^{* * *}$ \\
LF norm (n.u) & $55.94 \pm 3.23$ & $88.75 \pm 27.88$ & $0.000^{* * *}$ \\
HF norm (n.u) & $33.79 \pm 6.89$ & $22.34 \pm 5.82$ & $0.000^{* * *}$ \\
LF/HF & $1.72 \pm 0.36$ & $4.16 \pm 1.19$ & $0.000^{* * *}$ \\
\hline
\end{tabular}

Data were expressed as mean \pm \pm SD. Statistical analysis was done by Independent sample t-test. Group A=Control. Group B= Patients with Rheumatoid Arthritis.

$\mathrm{LF}=$ Low frequency. HF $=$ High frequency

$\mathrm{LF}(\mathrm{nu})=$ Low frequency in normalized unit $[(\mathrm{LF} /$ Total power-VLF $) \times 100]$

$\mathrm{HF}(\mathrm{nu})=$ High frequency in normalized unit $[(\mathrm{HF} /$ Total power-VLF $) \times 100]$

$\mathrm{LF} / \mathrm{HF}=$ Ratio of low frequency and high frequency power. $* * *=\mathrm{p}<0.001, *=\mathrm{pd}^{\prime \prime} 0.05, \mathrm{n}=$ number of subjects. 


\section{Discussion}

In the present study, findings of HRV parameters in healthy control group were almost within normal range and also similar to the published report from different countries. ${ }^{11,12,14,15}$ and also from our country. ${ }^{19-21}$

In this study, significantly higher resting pulse rate, diastolic blood pressure points comparatively higher sympathetic activity in RA which are similar to those findings reported by some researchers. ${ }^{22}$

Again, findings of Total power, HF and HF norm suggest lower parasympathetic activity and higher value of LF, LF norm and LF/HF indicate higher sympathetic activity in RA patients which are similar to those reported by some investigators of different countries. ${ }^{11,15}$

In addition, higher sympathovagal balance shows dominance of sympathetic activity in this group of patients.

Many explanations are suggested by different investigators for this involvement of autonomic nerve function activity in RA patients though the exact mechanisms are not yet clear. These suggestions like immune complex deposition, amyloid deposition, autoantibody production against nerve growth factor, cervical ganglia and vagus nerve may act as causative factors for this autonomic nerve function impairment in patients of the present series. ${ }^{10,17,23}$ But all of them were not possible to study due to some limitation.

\section{Conclusion}

From this study, it may be concluded that cardiac autonomic nerve impairment occurs in rheumatoid arthritis which is characterized by reduced vagal with higher sympathetic activity and shifting of sympathovagal balance towards sympathetic predominance.

J Bangladesh Soc Physiol. 2012, June; 7(1): 8-12

\section{Author affiliations}

1. *Kawser Jahan, Assistant professor, Department of Physiology, Shahid Monsur Ali Medical College, Ka-95/1Kuril Bishaw Road, Dhaka-1229. Email: kawserjahan64@yahoo.com

2. Noorzahan Begum, Professor, Department of Physiology, Bangabandhu Sheikh Mujib Medical University (BSMMU) Bangladesh. Email:noorzahan 52@gmail.com

3. Sultana Ferdousi, Associate professor, Department of Physiology, Bangabandhu Sheikh Mujib Medical University (BSMMU) Bangladesh. Email: sferdousiratna@gmail.com

*For correspondence

\section{References}

1. Voskuyl AE. The heart and cardiovascular manifestations in rheumatoid arthritis. Rheumatology [Internet] [cited 2010 May] 2006; 15(4): iv4 -iv7. DOI: 10.1093/ rheumatology / kel313

2. Statistics By Country For Rheumatoid Arthritis.[Internet] March 2005[Cited 2011] Available From: http://www.cureresearch.com/r/ rheumatoid_arthritis/stats-country printer.htm

3. Akil M and Amos RS. ABC of Rheumatology: Rheumatoid Arthritis-I: clinical features and diagnosis. BMJ 1995; 310: 587-90.

4. Altman RD. Rheumatoid Arthritis (RA): Joint Disorders: Merck mannual books of patient symptoms. Porter RS, Kaplan JL, Homeier BP (eds). [Internet]. [Update $2008 \mathrm{Feb}$; Cited 2009 Jun 24] Available From: http://www.merckbooks. com/symptoms/index.htm

5. Shiel Jr WC. Rheumatoid Arthritis. [Internet] 2010 [Cited 2010 September] Available From: http:// www.emedicinehealth.com/rheumatoid_arthritis/ article_em.htm

6. Kitas GD and Erb N. tackling ischemic heart disease in rheumatoid arthritis. Rheumatology 2003; 42:607-13.

7. Johns Hopkins Health Alerts .Rheumatoid Arthritis and your heart: Johns Hopkins health alerts offers heart- smart advice.[Internet]. 2008 [cited 2010] Available From: http://www.prweb.com/releases/ 2008/03/prweb779314.htm

8. Gerli R and Goodson NJ. Cardiovascular involvement in rheumatoid arthritis. Lupus 2005; 14:679. 
9. Acar G, Sayarlioðlu M, Akçay A, Sökmen A, Sökmen G, Yalçintap S, Nacar AB, Gündüz M, Tuncer C. Evaluation of atrial electromechanical delay and left atrial mechanical functions in patients with rheumatoid arthritis. Türk Kardiyol Dern $\mathrm{Ar}^{\circ}$ 2009; 37:4-10.

10. Louthrenoo W, Ruttanaumpawan P, Aramrattana A and Sukitawut W. Cardiovascular autonomic nervous system dysfunction in patients with rheumatoid arthritis and systemic lupus erythematosus. Q J Med 1999; 92:97-102.

11. Evrengül H, Dursunoglu D, Cobankara V, Polat B, Seleci D, Kabukeu S, Kaftan A, Semiz E, Kilic M. Heart rate variability in patients with rheumatoid arthritis. Rheumatol Int 2004; 24:198-202.

12. Kamal A. Assessment Of Autonomic function in patients with rheumatoid arthritis using spectral analysis 7 approximate entropy method. Neurosciences 2007; 12(2): 136-39.

13. Task force of the European society of cardiology and the north American society of pacing and electrophysiology, heart rate variability. Standards of measurement, physiological interpretation and clinical use. Circulation 1996; 93: 1043-65.

14. Anichkov DA, Shostak NA, Ivanov DS. Heart rate variability is related to disease activity and smoking in rheumatoid arthritis patients. Int J Clin Pract 2007; 61: 777-83

15. Milovanoviæ B, Stojannoviæ L, Miliæeviæ L, Vasiæ K, Bjelakoviæ B, Krotin M. Cardiac autonomic dysfunction in patients with systemic lupus, rheumatoid arthritis and sudden cardiac risk. Srp Arh Celok Lek 2010; 138: 26-32.

16. Kremers HM, Crowson CS, Therneau TM, Roger VL, Gabriel SE. High ten-year risk of cardiovascular disease in newly diagnosed rheumatoid arthritis patients: a population-based cohort study. Arthritis Rheum 2008; 58: 2268-74.

17. Maule S, Quadri R, Mirante D, Pellerito A, Marucco E, Marnone C, Vergani D, Chiandussi L \& Zanone M. Autonomic nervous system dysfunction in systemic lupus erythematosus and rheumatoid arthritis: possible pathogenic role of auto antibodies to autonomic nervous structures. Clin Exp Immunol 1997; 110:423-27.

18. Arnett FC, Edworthy SM, Bloch DA, McShane DJ, Fries JF, Cooper NS, Healey LA, Kaplan SR, Liang MH, Luthra HS. The American rheumatism association 1987 revised criteria for the classification of rheumatoid arthritis. Arthritis Rheum 1988; 31(3):315-24.

19. Kabir MR. Study On Heart Rate Variability In Patients With Hyperthyroidism. [Thesis][Dhaka (Bangladesh)]:BSMMU.2008.

20. Mithun S. Comparative study of cardiac autonomic nerve function status by heart rate variability between sedentary and heavy workers. [Thesis] [Dhaka (Bangladesh)]: BSMMU.2006 July.

21. Tabassum R. Assessment of cardiac autonomic nerve function status by heart rate variability in essential hypertension.[Thesis] [Dhaka (Bangladesh)]: BSMMU.2008 Jan.

22. Bidikar MP and Ichaporia RB. Autonomic (sympathetic) nervous system involvement in rheumatoid arthritis patients. Indian J Physiol Pharmacol 2010; 54(1):73-79.

23. Sandhu V and Allen SC. The effects of age, seropositivity and disease duration on autonomic cardiovascular reflexes in patients with rheumatoid arthritis. Int J Clin Pract 2004; 58(8):740-45. 